\title{
Social closure planning: scoping, developing and implementing - a case study
}

\author{
EF Heymann Anglo American, South Africa \\ PR Botha Anglo American, South Africa \\ CD Grant Anglo American, Australia \\ M January Anglo American, South Africa
}

\begin{abstract}
Social aspects often lag behind or are not factored into closure plans with the same rigour and levels of confidence as the physical and bio-physical aspects. Anglo American has a predominance of operations in developing countries where local communities become directly and indirectly dependent on the mining activities for their livelihoods. This emphasises the importance of proactive management of social aspects throughout the life-of-mine and at closure. Anglo American is of the opinion that a mine closure plan without concurrent social planning leaves a significant gap in the planning process, lowers the overall confidence in sustainable closure and increases post-closure residual risk as well as associated liabilities. The objective of this case study is to demonstrate how the Anglo American Mine Closure Team is assisting a coal mine in South Africa to develop its social closure plan and closure costs for the site. This is a significant departure from the norm where operations in the past have used external consultants. Using in-house resources ensures deeper ownership of the mine closure plan and thus a better chance that the plan will be executed as intended. The final social closure plan will address the needs and risks associated with employees and dependents, interested parties, affected parties and regulators. Understanding the needs and expectations of these stakeholders is essential to improve the confidence of the overall mine closure plan. The project to develop the social closure plan is split into three phases. The objective of phase one is to deliver a detailed scope of work, with actions, timelines, accountabilities and budgets, which will inform the development of the social closure plan component of the overall mine closure plan. The objective of phase two is to support the colliery with the execution of the actions identified in phase one to ensure the social closure plan is compiled to an acceptable level of confidence given the closure date for the colliery and that it is delivered within set timelines and budgets. The objective of phase three is to support the colliery to implement the social closure plan over the remaining life-of-mine and improve the level of confidence of the final closure plan, mainly through increased stakeholder engagement. Social closure criteria will be developed and included in the current stakeholder engagement platforms. The development of the social closure plan is managed as a project where gaps are identified, all required activities are mapped, resources assigned, critical paths identified and where the schedule is managed with rigour. Through this approach the challenge of involving a diverse array of internal and external stakeholders is much easier to manage. In addition, this multi-disciplinary approach allows for better integration and synergies between the social, physical, biophysical and financial closure planning.
\end{abstract}

\section{Introduction}

Planning for social closure often lags behind planning for physical and bio-physical aspects or is not factored into closure plans with the same rigour and levels of confidence as the physical and bio-physical aspects. Anglo American (AA) believes that planning for social closure should mainly be managed as an ongoing operational activity and that a mine closure plan without concurrent social planning leaves a significant gap in the planning process, lowers the overall confidence in sustainable closure and increases post-closure residual risk as well as associated liabilities. One of the key challenges related to social closure is the fact 
that it takes many years to establish sustainable socio-economic opportunities that will reduce the post mining socio-economic residual risk to an acceptable level.

The objective of this case study is to demonstrate how the AA Technical \& Sustainability (T\&S) mine closure team and the AA Government and Social Affairs (GSA) team are assisting Landau Colliery (see Section 2), which is three to seven years away from final closure, to develop a social closure plan for the site.

A review of the Landau mine closure plan revealed that the level of confidence in the plan is not at the level of confidence required in the Anglo American Mine Closure Toolbox (MCT) (Anglo Operations Propriety Limited 2013) in terms of the remaining life of the operation. It was determined that the area that needs the most attention to bring it to the correct level of confidence is the social closure component. The T\&S mine closure team was subsequently requested by the colliery to support them to develop a social closure plan which could improve the confidence level of the social component and be incorporated into the overall mine closure plan. To this end the T\&S mine closure team worked with the site to establish a project for the development of a social plan for the colliery.

The project is split into three phases. Phase one is to deliver a detailed scope of work, with actions, timelines, accountabilities and budgets, which will inform the development of the social closure plan component of the overall mine closure plan. Phase two is to support the colliery with the execution of the actions identified in phase one to ensure the social closure plan is compiled to an acceptable level of confidence given the closure date for the colliery and that it is delivered within set timelines and budgets. Phase three is to support the colliery to implement the social closure plan over the remaining life-of-mine and improve the level of confidence of the final closure plan, mainly through increased stakeholder engagement.

The final social closure plan will address the needs and risks associated with employees and dependents, interested parties, affected parties, and regulators. It is believed that the process of developing a social plan focusing on the needs of each stakeholder group will lead to a successful collaboration process with the stakeholders. To date there has been no specific engagement with these stakeholders on mine closure actions as current communication focusses on general information sharing due to the fact that no concrete social closure criteria have yet been developed.

\section{$2 \quad$ Background}

\subsection{Location}

Landau Colliery is located in the eMalahleni Local Municipality which falls within the Nkangala District Municipality of Mpumalanga Province, South Africa. The mine is located $10 \mathrm{~km}$ northwest of the town of eMalahleni. The mine comprises two geographically separate blocks, namely the 5,143 ha Navigation Section, located mostly south of the N4 highway, and the 6,387 ha Kromdraai Section, which is located approximately $4 \mathrm{~km}$ north of Navigation, as illustrated in Figure 1 (Golder Associates 2014).

\subsection{Production and life-of-mine}

The current operations at Landau consist entirely of open cast mining, with a production rate of 5 to 6 million tonnes per annum. Historic underground coal mining previously took place at both Navigation and Kromdraai. Mining activities at Kromdraai will continue to the end of 2018. The active rehabilitation programme at Kromdraai is planned to take three years post-mining. Although Kromdraai Section will close in 2018 there is a possibility that the life of one of the pits at Navigation Section may be extended to 2022. 

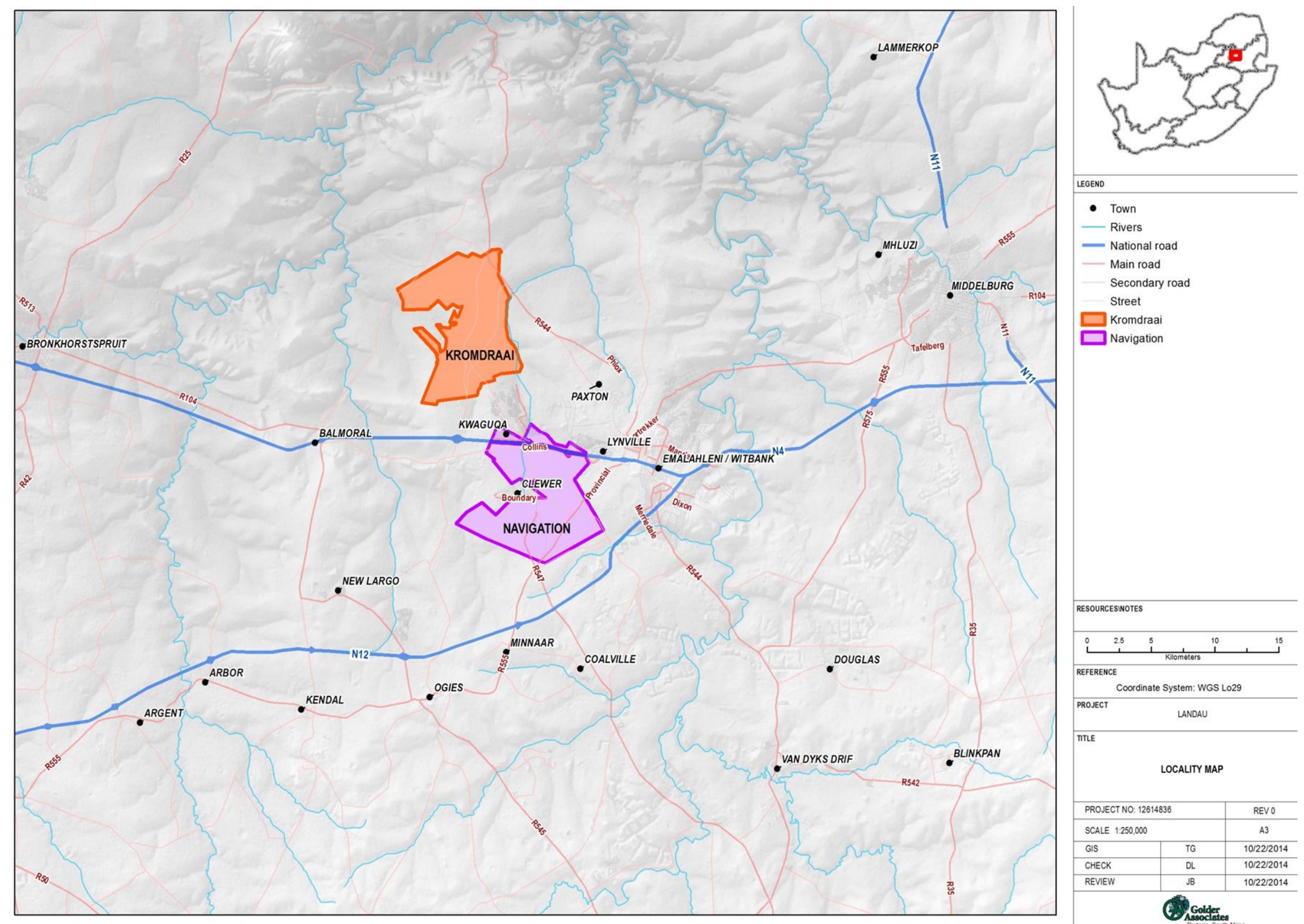

Figure 1 Landau Colliery location 


\subsection{Bio-physical context}

The climate of the area is one of summer rainfall with an average rainfall of about $690 \mathrm{~mm}$ per annum and the area experiences maximum temperatures of approximately $27^{\circ} \mathrm{C}$ in February with the minimum recorded temperature of approximately $2^{\circ} \mathrm{C}$ in July. The colliery elevation is at around 1,500 metres above mean sea level (mamsl).

Komdraai and Navigation sections are drained by various creeks which eventually flow into the Olifants River, which is the main river in the area. Groundwater users in the vicinity are largely limited to homesteads and smallholdings, who abstract water for domestic use purposes, although some abstraction for subsistence and commercial agriculture also occurs. Currently about $8 \mathrm{Ml} /$ day of acidic water from discard dump toe-seep and decant from rehabilitated voids requires treatment.

Prior to mining, $64 \%$ of the land had arable potential and $24 \%$ had grazing potential. The majority of the areas to the northeast, north and west of Kromdraai and to the west of Navigation are still mainly used for dryland agricultural purposes, as well as irrigated crop production and grazing.

Only one threatened plant species has been recorded within Kromdraai, namely the endangered dwarf succulent Frithia humilis. Invasion by exotic floral species, specifically Black Wattle, is rife.

Despite being highly transformed in various places, the mining area still supports a rich diversity of vertebrate fauna. This may be ascribed to the fact that parts of this area are situated between grassland and savannah, with species typical of both biomes being present here.

\subsection{Socio-economic context}

The largest population in the vicinity of Landau is in eMalahleni with a population of 395,466 individuals, which is about $10 \%$ of Mpumalanga Province population. Apart from the population in eMalahleni, there are a number of other townships, informal settlements and individual households within and surrounding the colliery mining right area. The main townships include Kwa-Guqa, Lynville and Clewer. Kwa-Guqa is located on the northernmost section of Navigation and Clewer is partially enveloped by Navigation's western boundary.

Education levels are low with approximately $26 \%$ of the adult population having no education. The unemployment rate is approximately $27 \%$ for the economically active (15-65 years), however, for the youth (14-35 years) the unemployment rate is 36\% (Statistics South Africa 2011). The youth constitutes $43 \%$ of the population in eMalahleni. The three largest economic sectors for eMalahleni include Trade (21.1\%), Mining (20.6\%) and Manufacturing (14.2\%) (eMalahleni c. 2015).

eMalahleni contributes $17.9 \%$ of the GDP of Mpumalanga Province and is the third largest economy in the Province (eMalahleni c. 2015). Census 2011 showed a growth rate of 3.3\% for eMalahleni, which is up from 2.8\% the previous census in 2001 (Statistics South Africa 2011). The economic dominance of eMalahleni has the potential of influencing population migration from nearby localities thereby putting a strain on the provision of job opportunities and basic services. Growth and development within neighbouring municipalities is therefore a key priority at the district level.

\subsection{Employees}

In 2015, the workforce comprised a total of 540 permanent employees and an additional 754 contractors. Of the permanent employees less than $5 \%$ are migrant workers from remote labour sending areas. The colliery provides no accommodation on site and employees live mainly in eMalahleni, Clewer and Kwa-Guqa. The functional literacy rate of employees is $98 \%$ or higher. 


\subsection{Social aspects related to closure of the colliery}

Key social issues that must be taken into account in the social closure planning for the colliery are (Golder Associates 2014):

- Mine workers and their dependents are financially reliant on the mine, which will impact upon their livelihoods at closure.

- Civil and municipal services in the area are currently under pressure as a result of urban expansion and insufficient maintenance, hence end land uses must seek to be self-reliant where possible, so as not to place additional strain on existing service networks.

- Ongoing expansion of informal townships along the edges of existing settlements onto surrounding open land may influence potential end land uses of the mine site, especially where illegal settlement occurs.

- The mine and immediate surroundings currently have limited existing and future tourism development opportunities due to the lack of natural and cultural historic amenities, which must be taken into consideration when identifying potential end land uses of the mine site.

- The geographical separation of the Navigation and Kromdraai mining areas and their differing life-of-mines (LoMs) will likely require different future spatial development planning prerogatives, specifically as Kromdraai is located in a more rural locality.

- Extensive mining regionally and on site has impacted the 'sense of place' of the area and needs to be taken into consideration if tourism/recreational end land uses of the site are planned.

- Economic development in the region will need to diversify into other sectors, as mining can be expected to contract in the future as reserves become depleted. End land uses and associated skills redevelopment and training must align with regional trends in this regard.

- A large percentage of younger inhabitants in the region may benefit more from end land uses that offer a larger number of semi-/unskilled employment opportunities than development that relies on highly skilled or educated workers.

The existing townships situated in the vicinity of the mine can be expected to continue growing for the foreseeable future, due to natural population growth and continued immigration of people seeking employment in the nearby eMalahleni and at other mines. This factor needs to be taken into consideration when identifying future land uses of the mine site, especially as these settlements are likely to encroach onto any available open land regardless of potential future planning.

\subsection{Post-closure land use}

The post-closure land use vision for the colliery is to progressively reinstate an end landscape that improves local spatial development patterns while maintaining a conservation-orientated focus where appropriate, by integrating rehabilitated wilderness areas and permanent post-mining landforms with the surrounding context in an aesthetically appropriate manner. End land uses must be self-sustaining and maximise socio-economic opportunities socially acceptable to stakeholders and integrated with the existing urban development context.

Likely end land uses at Kromdraai are dry land cultivation, grazing, forestry, wildlife conservation and an ecological conservation corridor. At Navigation, which is closer to current towns and villages, likely end land uses are mixed use light industry and residential with some limited dry land cultivation and grazing. 


\section{Development of the social closure plan}

\subsection{Context}

As the colliery is within three to seven years from closure, the MCT requires it to have a 'detailed' or 'final' closure plan. A detailed closure plan is required between ten to five years from closure and a final closure plan when closure is in five or less years. In terms of the MCT, a detailed closure plan from a social point of view requires 'proven' (see Table 1) social and health needs with authorities, employees, affected and interested parties through involved consultation. It furthermore requires a Class 1 closure cost estimate (-15 to $25 \%)$ for physical, biophysical and social closure components.

Table 1 Social (and health) needs criteria definitions

\begin{tabular}{ll}
\hline Criteria & Definition \\
\hline Assumed & $\begin{array}{l}\text { The requirements of Interested and Affected Parties (I\&APs), government and employees, } \\
\text { as well as the social closure criteria and final land use have been assumed and only a rapid } \\
\text { health impact assessment (HIA) has been carried out. No consultation has taken place. }\end{array}$ \\
\hline Assessed & $\begin{array}{l}\text { Social studies have been conducted and the potential closure impacts and mitigation } \\
\text { measures identified. A current HIA is in place; ongoing occupational health risk } \\
\text { assessments (HRA) are conducted. The operation's employees' capabilities and career } \\
\text { aspirations are known. The baseline environmental conditions are known and the wider } \\
\text { strategic socio-economic opportunities and constraints have been identified. A SD } \\
\text { vision/closure vision with underlying principles has been described. }\end{array}$ \\
\hline Confirmed & $\begin{array}{l}\text { The previously identified socio-economic needs, including the HIA, as well as the SD } \\
\text { vision/closure vision are well recognised. These aspects have been discussed with } \\
\text { employees and I\&APs and updated accordingly. A future forum consisting of management, } \\
\text { employee, union and community representatives is in place. }\end{array}$ \\
$\begin{array}{l}\text { The confirmed social closure requirements and final land use objectives have been } \\
\text { identified in more detail and re-confirmed through I\&AP and government involvement. } \\
\text { Impacts on community health are managed with key stakeholders. An employee } \\
\text { development and redeployment plan, taking into account the remainder of the business } \\
\text { plan, as well as employees' individual social needs, are in place. }\end{array}$ \\
$\begin{array}{l}\text { The authorities have agreed to the socio-economic closure plan, including health and } \\
\text { human resources, and other I\&APs have been consulted. A review of the health } \\
\text { components is conducted by an independent agency at stipulated intervals. There is a } \\
\text { majority agreement with the social closure plan. }\end{array}$ \\
Agreed
\end{tabular}

In terms of the MCT, a final closure plan from a social point of view requires 'agreed' (see Table 2) social and health needs with authorities, employees, affected and interested parties through collaborative consultation. It furthermore requires a Class 2 closure cost estimate (-5 to $15 \%)$ for physical, biophysical and social closure components.

A review of the Landau mine closure plan revealed that the level of confidence in the plan is not at either a detailed or final level of confidence and that the area that needs the most attention to bring it to the correct level of confidence is the social closure component. The AA T\&S mine closure team was subsequently requested by the colliery to support them to develop a social closure plan which could improve the confidence level of the social component and be incorporated into the overall mine closure plan. To this end, the AA T\&S mine closure team worked with the site to establish a Project Initiation Document (PID) in which the objectives, methodology and final deliverables of the project were described. 
It was agreed that the social closure plan will address the needs and risks associated with four key groups of stakeholders, namely employees and dependents, interested parties, affected parties and regulators. Understanding the needs and expectations of these stakeholders is essential to improve the confidence of the overall mine closure plan. It was furthermore agreed that closure criteria will be developed and included in the current stakeholder engagement platforms. What can and cannot be achieved at closure should drive the interaction with stakeholders.

\subsection{Project phases and objectives}

The project is split into three phases as follows:

- Phase 1: Deliver a detailed scope of work for the development of the social closure plan. The objective of this phase is to deliver a detailed scope of work, with actions, timelines, accountabilities and budgets, which will inform the development of the social closure plan component of the overall mine closure plan.

- Phase 2: Development of the social closure plan. The objective of this phase is to support the colliery with the execution of the actions as identified in Phase 1 to ensure the social closure plan is compiled to an acceptable level of confidence given the closure date for the colliery and that it is delivered within set timelines and budgets.

- Phase 3: Ongoing support to implement the social closure plan. The objective of this phase is to support the colliery to implement the social closure plan over the remaining LoM and improve the level of confidence of a final closure plan over the next three to five years, mainly through increasing the level of stakeholder engagement, moving from 'consulted' to 'collaborate' (see Table 2). Even though the objective is to collaborate, it is for items that are realistic and which meet the regulators requirements.

\section{Table 2 Consultation criteria definitions}

\section{Criteria}

No specific No consultation specific to mine closure planning is required at this stage, as there is not consultation a sufficiently detailed closure plan around which to consult.

Informed

I\&APs, government and employees have been informed of the mine closure plan by providing them with balanced and objective information of the issues, alternatives and/or solutions to enable them to submit their issues and concerns.

Consulted I\&APs, government and employees have been given the opportunity to review the revised mine closure plan and be part of the closure plan development, by means of ongoing consultation with the operation. Feedback from stakeholders on issues, alternatives and/or decisions has been considered and incorporated into the closure plan, where appropriate.

Involved I\&APs, government and employees are directly involved throughout the process to ensure that issues and concerns are consistently understood and considered, and offered the opportunity to make substantive changes to the closure plan and its criteria.

Collaborate The authorities, employees and other I\&APs have been in partnership with the operation in each aspect of the decision-making process, through which majority agreement with the mine closure plan and its final post-closure goals has been obtained. 


\subsection{Project resources}

A mix of on-mine, AA Coal and AA corporate resources are being used in this project. It is critically important that the on-mine team takes ownership of the project as they are going to be accountable for its implementation. On-mine functions are represented by human resources, health, community development, social performance, safety and environment. The AA Coal regional community development function is also represented on the project. The overall project is being managed by the AA T\&S mine closure team with assistance from a representative of the AA GSA team.

As social closure is viewed largely as an operational activity, the importance of reviewing and improving current social activities and social projects, to maximise the reduction of post-closure residual social impacts, are critical to successful social closure and obtaining the best value from allocated resources and funds. Empowering the onsite team and having clear accountabilities and responsibilities associated with the development of the social closure plan are two key success factors.

\subsection{Project execution}

\subsubsection{Phase 1}

Phase 1 commenced in March 2015 and was completed by the end of April 2015. It was delivered through the following key sequential steps:

1. Approval of the PID by colliery general manager. Making sure that the onsite team understands the business case for doing the work and own the plan was critical to the success of this phase.

2. Determining participation requirements of key mine functions. Having the appropriate team and cross-discipline representation were also critical to the success of this phase.

3. Initiation of project through a site visit to the mine by the mine closure and social affairs teams to discuss phase 1 work allocation and requirements.

4. Conducting an issues and gap analysis workshop to identify the current issues and gaps related to social closure (Table 3).

5. Developing an action plan to address the identified issues and gaps. After identifying the social issues and gaps related to closure a set of actions to address these issues and gaps for each stakeholder group were identified (Table 3).

6. Scheduling the identified actions in an action plan with key dates, durations, accountabilities, deliverables and additional budget and resource requirements in conjunction with the on-mine team. The importance of a rigorous process in managing and tracking the progress of the project actions cannot be underestimated. Figure 2 illustrates a snapshot of the action plan with key dates, durations, and additional budget and resource requirements for the first six actions for employees and dependents.

7. Finalising the project plan.

8. Signing-off the project plan. 


\begin{tabular}{|c|c|c|c|c|c|c|c|c|c|c|c|c|}
\hline$\#{ }^{\text {Task Name }}$ & Duration & Start & Finsh & $\begin{array}{l}\begin{array}{|l}\text { Progress so odate } \\
\text { log completel }\end{array} \\
\end{array}$ & Resource Names & \multirow{2}{*}{\multicolumn{4}{|c|}{ RACI }} & Deliverable & 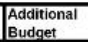 & 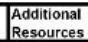 \\
\hline 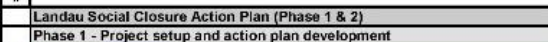 & \begin{tabular}{|lll}
190 days \\
39 ddys
\end{tabular} & 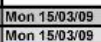 & 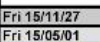 & $\frac{11 \% \%}{10 \%}$ & & & & & & & & \\
\hline 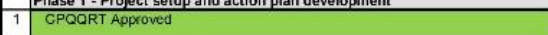 & 每 dayys & Mon 15101030309 & 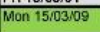 & $100 \%$ & Waram,Ruoloph & & & & & & & \\
\hline \begin{tabular}{|l|l|l|l}
2 & Socilal Closure Gap Anaysis \\
\end{tabular} & odays & Fri 15:03/20 & Fri 15:03/20 & $100 \%$ & Mariam,Rudoloh,.Agathe & & & & & & & \\
\hline \begin{tabular}{|l|l|l|l}
3 & Complite Gap Analysis Spreadsheet \\
\end{tabular} & 8 days & Fri 15:03/20 & Tue 15:03/31 & $100 \%$ & Erich,Mariam, Rudolph,Agathe & & & & & & & \\
\hline 4 Develop drat accion plan and schodubi for discussion and update & 5 days & Wod 15:04:01 & Tue 15:04:07 & $100 \%$ & $\begin{array}{l}\text { Agathe, Erich.Geralda, } \\
\text { Mariam,Rudolph }\end{array}$ & & & & & & & \\
\hline 5 Meethngs with onsile champions on lasks. schedulue and resources & 2 days & Thu 15:04:09 & Fin 15:04:10 & $100 \%$ & Erich,Mariam & & & & & & & \\
\hline 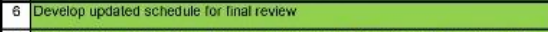 & 6 cays & Mon 15:04:13 & Mon 15:04:20 & $100 \%$ & Exich.Mariam & & & & & & & \\
\hline 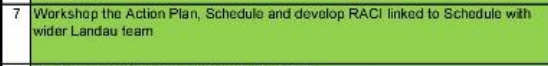 & 1 day & Tue 15:04:28 & Tue 15:04:28 & 100\% & 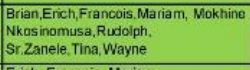 & & & & & & & \\
\hline \begin{tabular}{|l|l|}
8 Final agread action plan, schadule and RACI \\
\end{tabular} & 1 day & Wed 15:04:28 & Wed 15:04/28 & $100 \%$ & 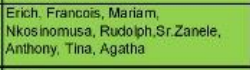 & & & & & & & \\
\hline \begin{tabular}{|l|l|}
9 & Establish a Mine Closure Committec \\
\end{tabular} & 1 day & Thu 15:04:30 & Thu 15:04:30 & $100 \%$ & Viay & & & & & & & \\
\hline 10 Present to GM tor signoff & 1 day & Thu 15:04:30 & Thu 15:04:30 & $100 \%$ & viay & & & & & & & \\
\hline \begin{tabular}{|l|l|} 
End o o phase 1 \\
\end{tabular} & o days & Fin 15:05:01 & Fin 15:050101 & $100 \%$ & Rudolph & & & & & & & \\
\hline 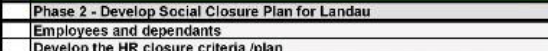 & $\begin{array}{l}\frac{190 \text { days }}{900 \text { days }} \\
87 \text { days }\end{array}$ & 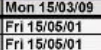 & 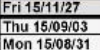 & $\frac{9 \%}{25 \%}$ & \begin{tabular}{|l|l} 
Wayne \\
Wayne
\end{tabular} & Responsible & Accoun & I consulted & Intormed & & & \\
\hline 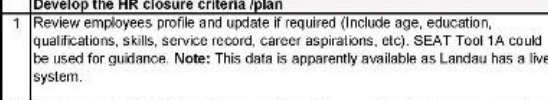 & $\begin{array}{lll}\frac{87}{42 \text { days }} \\
2 \text { days }\end{array}$ & 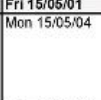 & 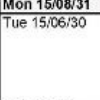 & 60\% & $\begin{array}{l}\text { Whayne } \\
\text { Wayne }\end{array}$ & Phinah Nogashioa & Wayne Harris & GSS & $\begin{array}{l}\text { Sitering and } \\
\text { clesurut } \\
\text { committeos }\end{array}$ & 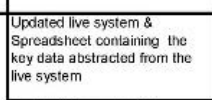 & ne & one \\
\hline 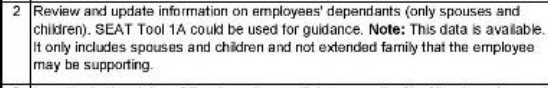 & 65 days & Man 15:05:04 & Fin 11507/31 & 50\% & Wayne & Phinah Mogashog & Wayna Harris & GSS & $\begin{array}{l}\text { Siterang and } \\
\text { clasurum } \\
\text { commitiees }\end{array}$ & 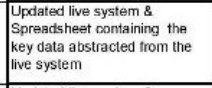 & None & None \\
\hline 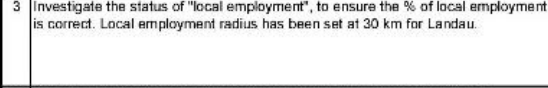 & 65 days & Man 15:05:04 & Fin 15:707/31 & $10 \%$ & Wayne & Phinah Mogastoa & Wayne Harris & GSS & $\begin{array}{l}\text { Sitering and } \\
\text { clessurg } \\
\text { commitees }\end{array}$ & 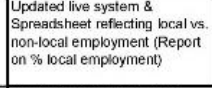 & one & None \\
\hline 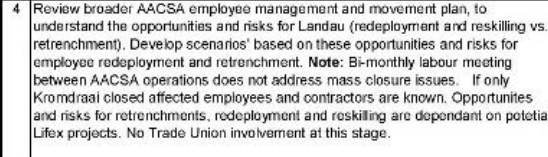 & 42 days & Fri 15:05:01 & Mon 15:06:22 & $60 \%$ & Wayne & Anthony Mqobokazi & Wayne Harris & Regional HR & $\begin{array}{l}\text { Sitering and } \\
\text { closury } \\
\text { commititees }\end{array}$ & 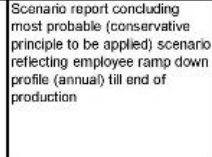 & & ione \\
\hline 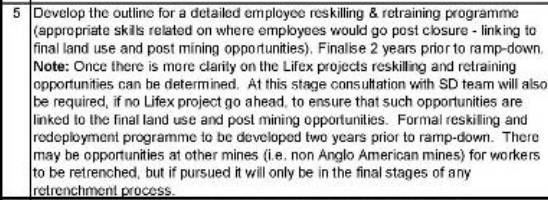 & 23 days & Tue 15:06:30 & Thu 15:077/30 & $0 \%$ & Wayne & Genthard Bester & Wayme Harris & Mokhine, Tina & \begin{tabular}{|l} 
Silecering and \\
closure \\
commitites
\end{tabular} & 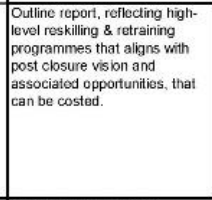 & & \\
\hline 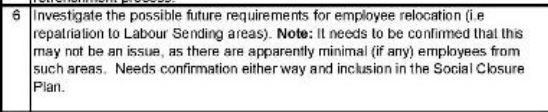 & 13 days & Wed 15:07/01 & $\mid F \overrightarrow{111507 / 17}$ & 10\% & Wayne & $\begin{array}{l}\text { Anthony Mqabokokzi, } \\
\text { Phinah }\end{array}$ & yne Haris & GSS & $\begin{array}{l}\text { Sitering and } \\
\text { closure } \\
\text { commititees }\end{array}$ & 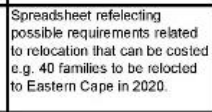 & & \\
\hline
\end{tabular}

Figure 2 Snapshot of schedule, RACI, deliverables and additional budget and resources 


\section{Issues and gaps identified}

\section{Employees and dependents}

- No detailed post-closure health risk assessment available to determine possible post-closure issues.

- A re-skilling programme is required to empower ex-employees to work outside of the mining industry.

- Dependencies created due to the company subsidised HIV programme.

- Sustainability of health infrastructure in rural areas from where some labour is sourced (labour sending areas) post-closure.

- Expectations that current employees' dependents will be employed when employee retires.

- Dependencies created through Social and Labour Plan (SLP) and Corporate Social Investment (CSI) programmes.

- High level of dependents per employee.

- Post-closure impacts on contractors and permanent contract employees.

- No closure specific consultation with employees or dependents.

\section{Affected parties}

- Post-closure sustainability of CSI projects and its effectiveness to address residual impacts.

- Socio-economic programmes focus on current issues and do not address post-closure social risks.

- Consideration to be given to new initiatives so as to not increase the dependency of communities on the mine.

\section{Actions identified to address gaps and issues}

Employees and dependents

- Review and update employees' profiles and information on employees' dependants.

- Investigate the status of local employment.

- Review Coal SA employee movement plan for redeployment and reskilling opportunities.

- Develop an employee reskilling and retraining programme - link to post mining land use.

- Investigate possible future requirements for employee relocation and repatriation.

- Consult with contractors to understand their policies related to redeployment and retrenchment.

- Develop plan to reduce employee dependency where it exists.

- Develop a critical skills retention plan.

- Conduct an employee health risk assessment (HRA), then develop a post-closure employee health management plan based on the HRA outcomes.

- Investigate the adequacy of public health infrastructure and services in labour sending areas.

- Evaluate affordability of post redundancy medical aid.

\section{Affected parties}

- Update current socio-economic impact assessment to understand the socio-economic impacts post mining.

- Review existing community HIA internally to identify long-term health impacts related to ongoing exposures post-closure.

- Determine post-closure sustainability of CSI and SLP projects. New projects to have a closure focus and should not create dependency. 
- Social closure plan must plan for, and address, post-closure social issues such as employment opportunities, skills development, reuse of infrastructure, safety, potential decline in local businesses etc.

- Zones of influence and stakeholder relationship-remapping required specifically for closure.

- Communication systems to be updated to include closure aspects.

- No closure specific consultation yet with affected parties.

- The Stakeholder Engagement Plan (SEP) to be updated to include the closure related components.

\section{Interested parties}

- There is a high risk that closure can become highly politicised due to the political climate of the time.

- The current closure related needs of interested parties have not been evaluated and are unknown.

- No closure specific consultation yet with interested parties.

\section{Regulators}

- Understand all closure related legal requirements.

- No closure specific consultation yet with regulators.
- Determine alignment of CSI and SLP projects with final land use and vision with a view to reduce post-closure residual risk.

- Update external stakeholder database from a closure point of view.

- Develop an integrated stakeholder engagement strategy for closure which includes all stakeholder groups.

- Review current operational social incidents to identify key risk areas and impacts and investigate the effectiveness of existing procedures.

\section{Interested parties}

- Update interested party database to include political parties, NGOs and CBOs.

- Determine which NGOs/CBOs could assist with or take over social projects post-closure.

- Evaluate public domain media coverage to gain an understanding of issues relating to closure.

- Evaluate external stakeholder reports for key expectations and concerns with regards to closure.

\section{Regulators}

- Update regulator database and legal register.

- Evaluate closure legal requirements. 


\subsubsection{Phase 2}

Phase 2 of the project commenced in May 2015 and is planned to be completed by the end of November 2015. Phase 2 is managed by the mine closure team against the project schedule as agreed in phase 1 with specific persons on mine accountable to achieve their deliverables. Bi-monthly project meetings are held where progress is discussed and tracked. Any issues in regards to slipping from the project schedule are discussed and plans to rectify are agreed. The project is tracked using proper project management principles and tools, including a MS project Gantt Chart (Figure 3) with a project 'action log', 'decision log' and 'lessons learned log'.

Using the MCT risk-based approach, once all the actions have been completed and the deliverables finalised, phase 2 will conclude with the following sequential steps:

1. Developing closure and success criteria for employees, affected parties, interested parties and regulators. Each of these key stakeholder groups have different closure needs and expectations, so the closure criteria should be focused on managing the residual risks for each of these stakeholder groups to an acceptable level.

2. Conducting a final risk assessment for each stakeholder group to identify additional gaps, if any. The costs associated with the selected social closure criteria will be evaluated against the benefit gained by either reducing the residual post-closure socio-economic risk level or by optimising a post-closure opportunity.

3. Determining the costs and resource requirements to execute the closure criteria for each stakeholder group. The focus is on using current operational spend on projects as part of corporate social investment, local economic development, reskilling and retraining projects in such a way that additional post-closure benefit could be realised without necessarily needing additional funds.

4. Compiling an individual social closure plan for each stakeholder group. As the various stakeholder groups have very different needs and expectations, the stakeholder engagement plan should reflect what will be discussed and with who, to what level of detail, and when, to ensure an improvement in confidence of the social closure plan and hence the overall mine closure plan.

5. Conducting a workshop where the collective social closure criteria and risks for all four stakeholder groups are finalised through filling any gaps and elimination of overlaps. Having a well-defined closure vison with objectives and underling principles to form the basis against which all stakeholders get measured.

6. Updating cost and resource requirements for the combined social criteria.

7. Integrating the four individual plans into one document, taking cognisance of the outcomes of the previous two steps.

8. Reviewing and updating the social plan.

9. Issuing the final report which must be integrated into the overall mine closure plan. 


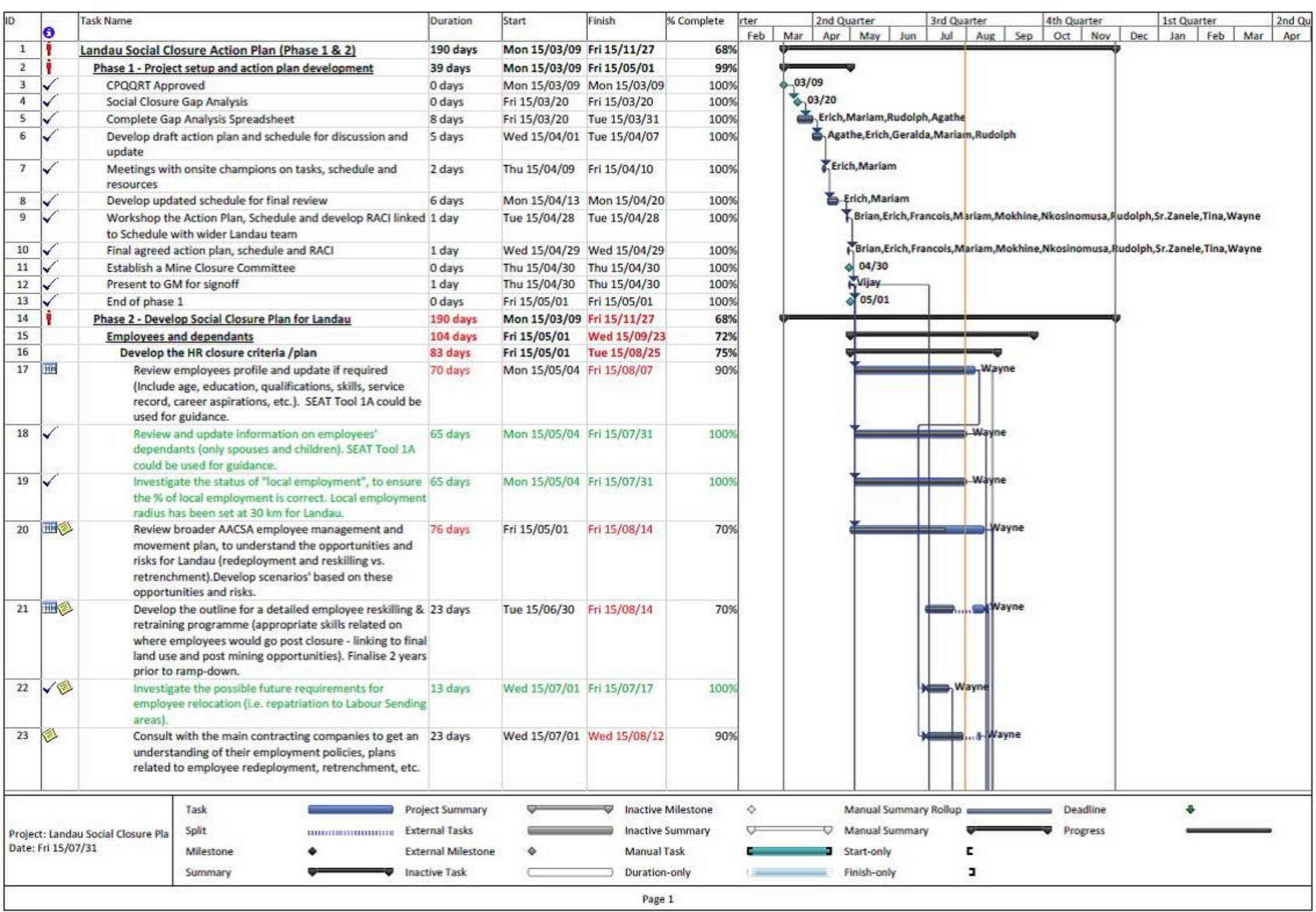

Figure 3 Snapshot of Gantt schedule 


\subsubsection{Phase 3}

Phase 3 will commence in 2016 and the aim is to support the colliery with the implementation of the social plan. A key component of this phase consists of stakeholder engagement at the level required by the MCT (i.e. moving from consulting to involving and eventually reaching a collaborative engagement process). Increasing the level of stakeholder engagement and transferring the acceptability/ownership of the overall closure plan, based on a well-defined closure vision and land use plan from the mine to the people that will remain in the area post mining, is the key to leaving behind a positive legacy. To this end a SEP in which the social closure and success criteria are integrated will be required. It is planned to achieve such a SEP by following the steps below:

1. Conducting a workshop to determine to what extent the current SEP must be updated based on the social plan developed in phase 2 .

2. Updating the current SEP based on the developed social closure plan and the workshop outcomes.

3. Determining and including costs for all planned stakeholder engagement in the SEP.

4. Finalising, reviewing and updating SEP.

5. Issuing the SEP and subsequent execution.

\subsection{Critical success factors}

Although phase 2 of the project has not yet been completed, phase 1 was successfully completed on time thanks to:

- Acceptance of ownership and accountability for development of the social plan at site level.

- Clear understanding of the need and importance of an appropriate social closure plan as a key component of the overall mine closure plan.

- Clear understanding of the business case and need to evaluate the current operational social spend against the benefit gained by either reducing the residual post-closure socio-economic risk level or by optimising a post-closure opportunity.

- Ongoing collaboration and trust between T\&S mine closure team, AA government and social affairs team, and the colliery senior management team.

- Availability of onsite resources to do the work required while still attending to their normal daily tasks.

The success of phases 2 and 3 will be measured through:

- Full integration of the social closure plan into the overall mine closure plan.

- Operational social costs for final three years defined and included in operational budgets.

- Final social costs at closure and post-closure defined and provided for in-closure and post-closure cash flows.

- Agreement of the social plan by the regulators and majority agreement by other stakeholders after collaborative consultation over the next few years.

- Ongoing and effective stakeholder interaction during the pre-closure, closure and post-closure phases of the colliery. To this end the Future Forum which has been established by the colliery in compliance with the Mineral and Petroleum Resources Development Act 2002, as amended, will be used as the primary vehicle for formal stakeholder engagement on all aspects of mine closure going forward.

Ownership transfer of the closure plan and its vision form the mine to the stakeholders that will remain in the area post mining 'cradle to cradle' philosophy. 


\section{Conclusion}

The development of a detailed project plan with detailed actions, clear accountabilities, resources and timelines is critical to ensure that an appropriate social closure plan is developed and incorporated into the overall mine closure plan at the appropriate level of confidence. It also facilitates the timeous implementation of the social closure plan and enhances collaborative engagement with the four key stakeholder groups.

The development of a social closure plan should use proper project management principles and tools, including project schedules (Gantt Charts and critical path views) with a project 'action log', 'decision log' and 'lessons learned log', turning something that is normally difficult to quantify and manage into a manageable project with a well-defined scope.

Social closure should be seen largely as an operational activity. The importance of reviewing and improving current onsite operational activities and social projects, to maximise the reduction of post-closure residual impacts, are critical to successful social closure and obtaining the best value from allocated resources and funds 'spending the same money wisely'. Empowering the onsite team and having clear accountabilities and responsibilities associated with the development of the social closure plan forms a very important success factor.

It is critical to ensure that the mine closure development team covers all disciplines across the various functional levels, take ownership of the project and develop a social closure plan that would be acceptable from a financial and residual post-closure risk point of view, prior to starting an external stakeholder engagement process to improve the overall confidence of the social closure plan towards final closure.

Increasing the level of stakeholder engagement and transferring the acceptability/ownership of the overall closure plan, from the mine to the people that will remain in the area post mining, based on a well-defined closure vision and land use plan, is the key to leaving behind a positive legacy.

\section{Acknowledgement}

The authors thank and acknowledge the mine manager, Bonke Ntimane and his team, for giving us the opportunity to work with them on this project to develop a social closure plan for their operation. Their enthusiasm and sustained level of effort during the entire process is acknowledged given that their input into this project was made over and above their daily tasks.

\section{References}

Anglo Operations Propriety Limited 2013, Mine Closure Toolbox, software, version 2, viewed 26 August 2015 , http://www.angloamerican.com/sustainability/environment

eMalahleni c. 2015, 2015/16 Draft Integrated Development Plan, eMalahleni, viewed 28 October 2015, http://www.emalahleni.gov.za/online2/index.../13-idp-sdbip?...draft-idp-2015-16

Golder Associates 2014, Preliminary Mine Closure Plan for Landau Colliery, Report Number: 12614836-12410-6, Johannesburg.

Statistics South Africa 2011, eMalahleni, Statistics South Africa, viewed 10 September 2015, http://www.statssa.gov.za/ ?page_id=993\&id=emalahleni-municipality- 2 . 
